\title{
Imagining the Kenyan Canaan dream journey in cyber space
}

With technological advances made in contemporary times, new literary genres have emerged in digital space, with an attendant rise in the performance of rhetorical discourse on social media platforms. In the run up to Kenyan elections on 8 August 2017, the opposition leader Raila 0dinga, whose father Jaramogi Oginga Odinga wrote a book titled Not Yet Uhuru, packaged himself as the biblical Joshua with a quest to liberate Kenyans and take them to the Promised Land, Canaan. This biblical analogy depicted in Odinga’s speeches propelled Kenyans to engage in creative descriptions of the Canaan journey using social media. This play on imaginings of a Canaan journey, as displayed in cyber space, became a performance of biblical analogies, dreams, and expectations by rival characters in an ensuing online drama. In this article I examine the digital orality in the emergent texts found on Kenyan social media platforms as a form of online liveness. It focuses on social media exchanges that are inspired by Odinga's quest (as captured in his speeches) to take Kenyans to Canaan. Placed within the framework of online liveness studies, it analyses how, using digital media, spatially dispersed Kenyans shared creative memes, messages, and tweets that allowed them to vicariously undertake the Canaan journey online. I utilise Carl Jung's theory of archetypes and collective unconscious to explore the journey motif, framed within an analogy of the Israelites' journey from captivity, with Odinga portrayed as a hero who pursues the political quest of delivering Kenyans to the land of Canaan. Keywords: cyberspace, journey motif, emerging genres, online liveness, digital orality.

\section{Introduction}

Orality in the digital age is now a preoccupation of oral literature scholars alongside the earlier debates on oral literature vis-à-vis written literature. Over time, boundaries between written literature and oral literature have been blurred as new media bridges the divide between the two dichotomies. More so, African writers have appropriated oral literature material in their works integrating the two dichotomies. This led scholars like Ruth Finnegan to ask the question, "How oral is oral literature?" In response to her own question, she argues that oral literature can exist in conditions marked by marginal or even full literacy and some coexistence, or even interaction with, written literature is in practice the most common form as far as the corpus of collected or collectable material goes (59). She sets out the criteria upon which a text can qualify as oral, namely mode of composition, mode of transmission, actualisation in performance, and sources of the material. Thus, by weighing against the criteria, one can decide on the orality of a literary piece. However, such arguments were mostly based on traditional genres that are easily identifiable across many African communities but with limited assessment of the emerging genres among the technologically driven generation. In the contemporary world, more and more interactions are mediated by technology. Orality, which before could only be achieved through face-to-face interaction and within the same physical space, can be mediated through technology, allowing people dispersed all over the world to have an oral conversation. Kaschula argues that "the boundaries have been merged and what has emerged is perhaps a post primary, post-secondary culture that cultivates literacy, but also cultivates orality" ("Exploring the oral-written interface with particular reference to Xhosa oral poetry" 173 ). He notes that, despite oral and written literatures having a certain level of autonomy, they emanate from "the same culture and society and perform the same function of commenting on the society and the world in general" (174). With the general trend of the world moving towards the use of technology, Kaschula proposes the term 'technauriture' "as the attempt to capture the mo-

Kimingichi Wabende is a lecturer in the Department of Literature at the University of Nairobi, Kenya. His research focuses on oral literature and performance in East Africa.

Email: kwabende@uonbi.ac.ke

(D) https://orcid.org/0000-0002-4210-8189

D0l: https://doi.org/10.17159/tl..588il.8391

DATES:

Submitted: 26 May 2020; Accepted: 10 March 2021; Published: 14 May 2021 
dalities associated with the three-way dialectic between primary orality, literacy and technology [...] it includes technology that can be brought to bear on issues of orality, oral history [...] an attempt that human culture has evolved to be aware of the implications of technological advances" ("Technauriture as a Platform to Create an Inclusive Environment for the Sharing of Research" 47).

This article is set within online liveness studies and engages with mediatised performances on internet-based platforms. Auslander views a mediatised performance as "a performance that is circulated on television, as audio or video recordings, and on other forms based on technologies of reproduction" (4). In preparation for 2017 Kenyan general election, there arose two political groupings: the National Super Alliance (NASA) led by Raila Odinga and the Jubilee alliance led by Uhuru Kenyatta. The two formations were the main contenders for the political leadership of the country. My article focuses on the mediatised portrayal of the leader of one of the political formations, Odinga, and how he formulated and described a "Canaan journey" through his rhetoric while addressing 'live' audiences in public rallies, and the subsequent debates generated by his online audiences in various internet-based forums. As Kim argues, "In the age of social media, a recorded live theatre or film clip can facilitate online sharing and enable a broad wave of ongoing participation from spectators, rendering the time lapse between production and consumption meaningless" (10). In line with Kim, I analyse how the online Canaan debates led to the creation of two solid online political groupings: NASArites (those subscribing to a Canaan journey as members of the National Super Alliance, NASA) and Jubilants (those belonging to the Jubilee party and opposed to the Canaan journey). The groups developed a form of online discourse pursuant to their goals. I examine the discourse of these online participants as an illustration of increased significance of cyber space as a performance arena in technologically dependent economies.

In this article I further employ the Jungian theory of archetype and collective unconscious to explore the journey motif couched in biblical analogy of the Israelite's escape from captivity in Egypt to Canaan. I view the Kenyan quest for journeys and movements as a form of Jungian archetype (motif) in the context of what Jung regards as "an irreprehensible, unconscious, pre-existent form that seems to be part of the inherited structure of the psyche and can therefore manifest itself spontaneously anywhere, anytime [...] again and again" (23). A desire for freedom, both personal and political, has run through the veins of Kenyans and their psyche since the period of struggle for independence from colonialism. I assess the journey motif in line with Odinga's quest and how the imagining of a journey pushes Kenyans who join in the dream through participating in online discussions on the subject causes them to reflect on possibilities of transformation both at an individual and national level. Underlying my argument, as I explore how Odinga communicates the idea of the Canaan journey, is the notion of representation as espoused by Stuart Hall. Representation, Hall argues, "is an essential part of the process by which meaning is produced and exchanged between members of a culture. It does involve the use of language, of signs and images which stand for or represent things" (1). I thus explore what Odinga says in his Canaan journey speeches and how the online audience interprets what the speeches represent.

\section{Locating Kenyan political history through the biblical journey to Canaan}

In his quest to marshal Kenyans to his side during his political journey to the presidency as the opposition leader, Odinga sought to use biblical allusion in his speeches. He equated what Kenyans were experiencing in their lives to what the Israelites in the Bible underwent at the hands of the Egyptians before God sent Moses to rescue them. With Kenyans regarding the fight for the independence of the country as the first liberation, the second liberation is seen as the actualisation of personal freedoms and the attainment of human rights. The fight against colonialism (the first liberation), and the push for political space and personal freedom (the second liberation) both signify a major milestone in the Kenyan journey to nationhood. Naming them as the first and second liberations indicates a movement, which is the hallmark of any journey, whether in a literary sense or a physical sense. As Mortimer argues, "the voyager holds a promise of transformation, of broader horizon and a deeper knowledge" (169). In their journeys, Kenyans seek the opening of spaces for freedom in political, social, and economic spheres. This idea seems to recur in every generation as a movement. As Jung argues, "archetypes reflect human experiences" and they "can only be explained by assuming them to be deposits of constantly recurrent impressions made by subjective reaction" (23). Every decade in Kenyan history has represented a fight, a movement, or a struggle in their journey to achieve freedom and justice in the country. Having drawn a parallel between the second liberation movement in Kenya with the Israelites' journey to the Promised Land, Odinga took cognisance of the efforts of those who came before him in the struggle, like his father, Jaramogi Oginga Odinga, and the first president, 
Jomo Kenyatta. Kenyatta, Jaramogi Odinga, Daniel arap Moi, Masinde Muliro, and other Kenyan freedom fighters represent those who started the journey of liberation, which in this article I refer to as the first liberation.

This article draws a parallel between the biblical journey of the Israelites from Egypt to Canaan and the symbolic journey initiated by Odinga to take Kenyans to the dream of Canaan in his political endeavour. In the Bible it is said: "And the Lord said, I have seen the affliction of my people which are in Egypt, and I have heard their cry by reason of the taskmaster, for I know their sorrows; [...] Now behold, the cry of children of Israel is come unto me; and I have also seen the oppression where the Egyptians oppress them" (Exodus 3:7-9).

The suffering alluded to in this verse triggers the long journey of the Israelites from bondage in Egypt. The Kenyan people, for whom Odinga draws the analogy, suffered under British colonial rule. A statement released by the African Elected Members Organisation (AEMO) paints the state of the Kenyan people under colonialism, which Odinga's father described as a: "system which serves as a device to secure for certain people permanent political and economic domination of other sections of a community. [...] [W] shall fight to build a government and society in which all enjoy equal rights and opportunities, and no one enjoys privileges or a privileged position" (J. Odinga 150).

However, echoing people of his time, Jaramogi Odinga felt that Kenyatta was the real Moses and his own role at that time was to step into the vacuum created by the state of emergency when the spokesmen of the people had been imprisoned so "that Kenyatta and leaders with him in restriction could lead Kenya to independence, and that there would be no independence as long as the leaders of the people were locked up" (155). Jaramogi Odinga thus refused to take up the leadership mantle until Kenyatta was released. With the eventual release of Kenyatta, Jaramogi Odinga, together with the leading liberation movement leaders, led Kenya to its independence in 1963. This marked the first liberation, which was mainly a political liberation with the country remaining in many ways under the economic yoke of its former colonialists. The colonial administrative structures were inherited with only a change in guard, thus most of the restrictive and oppressive laws were retained, leading Jaramogi Odinga to write Not Yet Uhuru. These are the circumstances that called for the second liberation movement. It came at a time when the first liberators had handed over the mantle to second generation liberators. The Bible, in the book of Joshua, says: "Now after the death of Moses the servant of the lord it came to pass, that the lord spoke unto Joshua the son of Nun, Moses' minister saying: Moses my servant is dead; now therefore arise, go over this Jordan, thou, and all these people, unto the land which I do give to them, even to the children of Israel" (Joshua 1:1-2).

At the time of his quest for presidency, the opposition leader Raila Odinga thus portrayed himself as the Joshua - who took over from Moses - in his quest to lead Kenyans to the Promised Land of Canaan, described by the founders of the nation as a society in which all enjoy equal rights and opportunities. Thus, Odinga cultivated a narrative that demonstrated that his father and other opposition leaders in the earlier period of Kenyan history were representative of the struggle for the first liberation, just like the biblical Moses. This justified his role as Joshua whose responsibility it was to complete the second liberation journey.

The mobilisation of the so-called Canaanites. or NASArites as they were commonly referred to, cut across different categories of people, social status, and identities. Jung notes that "when a situation occurs which corresponds to a given archetype, that archetype becomes activated and a compulsiveness appears, which, like an instinctual drive gains its way against all reason and will" (102). In this case the journey towards freedom was activated and it ignited the imagination of Kenya towards symbolically travelling to Canaan. Heroes in the journey motif, as Mortimer points out, need a form of intercession to succeed, given the level of obstacles they encounter. This is further emphasised by Lawson, quoting Campbell, when he points out that "the hero must rely on the assistance of others encountered in the journey in order to overcome the challenges" (135).

Basing his journey on a religious doctrine, Odinga seeks mediation from religious institutions and thus attends church services. Within the audiences that he addresses, there are those who understand the Canaan journey as simply a biblical story and those who view the story through the religious significance it carries. To Christians, it demonstrates God's fulfilment of the promise made to the Israelites that he would save them from the cruelty of the Egyptians. Taking cognisance of how different audiences interpret his speeches in the context of the Christian faith, there is therefore a difference in how Odinga treats this biblical analogy while addressing public rallies and when he is in church.

While addressing public rallies, Odinga is safe to make direct reference, without fear of being questioned by his supporters, that their journey has a spiritual significance and the endorsement of God. He colours his role as both a religious and political quest by situating himself in the Bible and employing biblical images and characters. 
He spells out that role clearly during a rally at Uhuru Park on 5 August 2017, one of the public spaces used for political and social events in Nairobi.

I will be a president who only takes you across river Jordan because the Israelites are already out of Egypt and on the shores of Shama, through the jungle of Sinai and now they are on the banks of Jordan. I will be the Joshua to take them across river Jordan to Canaan. Once you get to Canaan, my task will be over.

Uhuru park is the symbol of Kenyan's independence as denoted by the meaning of the Swahili word "uhuru", meaning freedom (coincidentally the name of his nemesis who was born at independence). While addressing people within a space that signifies freedom and exemplifies what they seek in their Canaan journey, he defines his role as that of a transitional political leader. The Joshua in the Bible is only meant to complete the journey for Moses and he, Odinga, has a very specific task as a transitional and transformative leader to take Kenyans to Canaan. The Israelite Joshua undertakes his journey through physical travel over a long distance, while the Kenyan Joshua seeks to fulfil his promise through symbolic travel over a five-year presidential term by transforming his country into a Canaan. The idea of the journey and its different facets has taken on different interpretations since independence. I take note of Ferdinand Saussure's idea as quoted by Hall that "the relationship between the signifier and the signified, which is fixed by our cultural codes, is not permanently fixed. The concepts (signifieds) to which they refer also change, historically and every shift alters the conceptual map of the culture, leading different culture, at different historical moments, to classify and think about the world differently" (17). In Kenyan history and to different audiences that Odinga implores to join the Canaan journey, it signifies and represents different ideas in the minds of his listeners.

Conversely, while in church, Odinga pays closer attention to the details of the biblical story. He is careful to portray himself as a devoted Christian seeking intercession from the church without pricking on sensibilities of the congregation by equating himself to biblical figures. He therefore distances himself from the biblical story, only drawing a parallel between the two journeys. In church he says:

We are sure in our journey we will get to our destination. Didn't you say that the Canaan one was not easy, that Pharaoh had refused to release you from Egypt, he even sent soldiers after you when you left [...] They suffered in the jungle for many years [...] but Moses said they should not abandon the journey and many of those who left Egypt did not get to Canaan but the remaining ones led by Joshua and Caleb got to Canaan. (R. Odinga, "NASA leader Raila Odinga is confident of reaching Canaan")

Like a typical church sermon, Odinga's speech uses the biblical citation to illustrate an earthly example. In the above quote, he does not refer to himself directly as Joshua but allows the audience to infer that this historical moment could be equated to the biblical journey of the Israelites. He accommodates the congregation as fellow journeymen to win their sympathies by demonstrating that he is sympathetic with their situation. Odinga's use of religious analogies to woo Kenyans echoes Jung's argument of the power of archetypes in human life when he says:

Can we not see how a whole nation is reviving an archaic symbol, yes, even archaic religious forms, and how this mass emotion is influencing and revolutionizing life of an individual in a catastrophic manner But if we consider the tremendous powers that lie hidden in the mythological and religious sphere in man, the aetiological significance of the archetype appears less fantastic [...] Can we not see how a whole nation is reviving an archaic symbol, yes, even archaic religious forms, and how this mass emotion is influencing and revolutionizing the life of the individual in a catastrophic manner? (101).

Though the Canaan journey is not driven towards a negative end, I see a correlation with how the religious narrative is used as tool for mobilisation and the igniting of a Kenyan psyche. It is evident therefore that Odinga navigates through his different audiences' and followers' tastes by appropriately manipulating the same religious story to fit different contexts and thus firmly situates himself as a Kenyan Joshua pursuing a quest comparable to that of the biblical Joshua.

\section{Digital orality and online liveness}

While examining Odinga as a hero engaged in a quest and using his speeches as a foundation upon which the Canaan journey is premised, I also examine how audiences (NASArites and Jubilants) that watch the online videos engage with each other in Canaan online journey contestations. The audiences are akin to what Couldry views as 
a ritualistic collectivity of liveness, noting "l. that we gain access through liveliness to something broader, central, significant, which is worth accessing now, not later; 2 . that we who can gain live access is not random, but a representative social group; 3 . that the media [...] is the privileged means for obtaining that access" (356). Despite the groups not physically meeting and existing in different geographical spaces, they interact and exchange virtual verbal vibes and jibes through technologically supported internet orality and coalesce together as people with a common goal.

In his analysis of Swahili online orature, Mnenuka further advances the above argument, noting that "in the contemporary context, literary compositions and their presentations are not restricted to verbal and written modes only, because with advent and advancement in technology, there has emerged innovative modes that are well implicated in the presentation and dissemination of literary composition" (275). Technology has introduced new forms of media through which literary works are expressed and conveyed in addition to conventional forms. These media bring with them different ways of accessing and partaking of artistic works, including how the audiences interact and how the discourse is used in virtual performance spaces.

Arguing against the notion of the need for an audience to be physically present in an event or performance, Kim points out that "co-presence is not simply a matter of being in the same time and space; more crucially, it is a matter of social interaction brought about by the changes in media technology" (3). Dixon further proposes that "presence should be seen as a way to rethink liveness with a particular emphasis placed on the degree to which spectators pay attention to the events unfolding in front of their eyes, whether it be events involving the presence of live bodies or media image" (2l). This equally implies that the audience's reaction shifts from verbal to written and is permanently captured, unlike the live performance which, as an event, is temporal. The current nature of life and place is profoundly digital and internet-based, using portable gadgets ranging from laptops to mobile phones that allow communication among people who are not in spatial co-presence. In this context, the online audience is afforded a chance to watch Odinga's performance, with him as a performer that also has a live audience at a political rally. The performers, Odinga and his audience in the live spatial co-presence performance, thus become a singular spectacle to be watched by the online audience. The online audience views the whole rally as a staged performance in which the live audience existing in spatial co-presence displays their abilities and prowess.

\section{The Canaan online journey motif}

In this section I examine how Odinga's quest to take Kenyans to Canaan inspires an online symbolic physical journey to the Promised Land. Mortimer notes that "the physical voyage represents an intellectual and emotional initiation to maturity, the voyager's goal is to acquire the knowledge and/or power that will allow him or her to rejoin the community and enjoy the heightened status in it" (171). In undertaking this important symbolic physical journey, Odinga hopes that it will culminate in his ascendance to the presidency, a position of power that would allow him to initiate and implement reforms that would benefit Kenyans. According to the Bible, the people of Israel undertook a physical journey travelling over deserts, land, and seas to get to Canaan. In Exodus, the Bible says: "And the children of Israel journeyed from Ramser to Succoth, about six hundred thousand on foot that were then besides children. [...] God led the people about, through the way of the wilderness of the Red sea; the children of Israel went up harnessed out of the land of Egypt" (Exodus 12:36; 13:38).

The Kenyan journey is both symbolic and physical. The physical journey is, to a certain extent, seen in the act of the political campaign itself. Odinga undertakes a physical journey around the country urging his supporters to undertake the Canaan journey. His act, though physical, is an act in mobilising and gathering supporters to join him in a symbolic journey to Canaan.

I locate Odinga as a hero who inspires Kenyans through biblical allusion, giving his message a spiritual and religious context. Equating his quest to take Kenyans to the symbolic Canaan to the journey the Israelites undertook from Egypt - land of suffering and pain - to Canaan-Promised Land of milk and honey-he portrays himself as a Joshua leading that journey. Lawson, quoting Campbell, points out that:

The hero's journey is set in motion by means of a supernatural event that casts the innocent into a strange and unfamiliar arena [...] Those who choose to accept the call begin the journey from the known to the unknown. [...] Once the journey is underway, the hero faces many tests standing between him/her and the ultimate goal. [...] Those who can pass the tests of the journey demonstrate, through the journey itself, that they already possessed brains, courage and heart. $(134-5)$. 
Odinga designates his role as godly ordained by invoking biblical verses and enlisting Christians and fellow politicians in the pursuit of the Canaan dream. Kenyans, like Israelites, find themselves at a historic moment - choosing a leader through voting for the person who will liberate them from the ills that bedevil their country.

In turn, both Odinga's supporters and those who oppose his ideals play out the same journey on the internet using messages disseminated through tweets and WhatsApp messages. The interpretation of Odinga's message, though based on a biblical story known to many, varies. As Hall points out, "meaning depends on the relationship between things in the world-people, objects, events real or fictional-and the conceptual system, which can operate as mental representation of them" (4). Each camp therefore interprets the biblical analogy from the perspective of their religious or political affiliation. In explaining how archetypes are realised, Jung argues that they may come out through dreams, or what he refers to as "active imagination, that is, a sequence of fantasies produced by deliberate concentration" (102). Thus, Kenyans engage in this online active imagination of their Canaan dream journey through memes and texts. I use the word dream in the sense of aspirations as opposed to the Jungian dream.

Different means of transport that enable Kenyans to move within their country are envisioned as pathways that will allow NASArites or the Kenyan people in general to travel and enter Canaan. The means of transport imagined for this journey include walking, using public transport, train, taxis, and flying. The tweets come in both pictorial form and in words. One of the memes captures Odinga leading a large crowd. In his hand, he carries a stick like that of Moses in the Bible leading his flock to the land of Canaan. In another picture he looks like a Roman soldier with a sword, spear, and a shield—with his newfound name Joshua Rao-leading a multitude to Canaan (@VictorKipronoKl). In the two memes, the NASArites are seen to be undertaking the journey like the Israelites, on foot, led by their leader Odinga. He is presented as a leader who carries symbols of authority as interpreted from the Bible in the form of a sword or a walking stick. Therefore, the journey is not seen as an easy walk to freedom, but hazardous, whereby the followers must endure pain and suffering. The memes show a large crowd to portray the large following that their leader is assumed to command. This journey where they trek, despite it being the most basic and rudimentary, exemplifies solidarity in numbers as pictorially captured. It portrays the journey as a popular and inspired undertaking by the people of Kenya. Despite other means of transport being popular, this form shows a popular movement buoyed by people's enthusiasm to undertake the journey despite challenges as opposed to individualistic and class-based segregation in the choice of taxis or airplanes. It equally has a basis in the biblical argument that path that leads to heaven is full of thorns.

The journeying multitude is comprised of people with varied attitudes and degrees of patience. Those who lead the journey, like Moses, must endure accusations whenever they are out of sight of those they lead. To pray and consult God, Moses had to leave the Israelites behind. In the memes, Odinga, too, makes a temporary exit. His absence from the country was always punctuated with, "Baba while you were away". This phrase was a running popular tweet while Odinga took a three-week tour of the USA. Known for his barbs against the government, many Kenyans felt the government took advantage of his absence to undertake unpopular actions. There was a rallying call for his return, where Kenyans on Twitter gave accounts of what he needed to know and deal with on his return. However, Odinga's opponents, the Jubilants, interpreted all Odinga's absences as an escape from responsibility. In a meme appearing in a tweet, a crowd carrying umbrellas is captured stranded at a big river with the caption, "NASArites stranded at river Jordan. Na JOSHUA amezima simu" (and Joshua has switched his phone off) (The Standard). Instead of Joshua being there to help the NASArites to cross the river, he has disappeared. The Jubilants also see the journey as a long trek but, rather than give it a positive interpretation, they present Odinga as a leader who will abandon his flock. They seek to show the opposition leader as untrustworthy and not worthy of being elected. The meme captures both the old and the new: while the biblical Moses overstayed in the mountains and therefore could not be accessed physically by Israelites, Odinga (Joshua) switches off his phone so that he cannot be reached by his followers electronically. Odinga's opponents seem to recognise the idea of a Canaan journey and the need for it, but do not aver to the choice of leader. It is a mixture of intertextuality and biblical allusions embracing items of modern technology that are relevant to a contemporary audience but still retaining the connotations of the biblical analogy.

Matatus (shared taxis), the most popular mode of transport in Kenya, feature in the Canaan journey as an option in terms of the means of transport that will take people to the dream of Canaan. Though typically Kenyan, they are also associated with unruliness, chaos, and disorder in urban centres. Most participants, unless portraying negativity against the opponent, seem to avoid the imagined use of matatu as a means of transport in 
the journey to Canaan. The matatus represent a bad past that the Canaan quest is escaping. Incidences that were considered as curtailing or providing obstacles in relation to entry into Canaan are equated to a matatu's failure to arrive at its destination. There were indeed various discussions between the NASA and Jubilee supporters on whether the journey had hit a snag whenever there was an obstacle. When it was declared that NASA had lost the elections on 8 August 2017, there was a meme of a matatu with the caption, "Trip to Canaan cut short by NTSA at Bondo. Journey to Canaan, chang'a Drunk Driver arrested" (Tuko news). The image of the matatu in the meme had a designated route of Nairobi-Bondo-Canaan emblazoned on its side. Bondo is the home village of NASA leader Odinga (Joshua). The meme shows his supporters, not only using a means of transport long discarded by Kenyans (an old Peugeot 504 pick-up) but also illustrates that it is overloaded, and it is driven by a driver who is drunk from an illicit brew (chang'aa). The depicted vehicle is not suitable for such a long-distance journey, and thus the image demonstrates that it was foolhardy for NASA supporters to use a vehicle intended for short distance travel in undertaking a journey to foreign lands, which thus led to their arrest by the National Transport and Safety Authority (NTSA).

Some Kenyans had envisioned undertaking the Canaan journey using private taxis that are portrayed to be more prestigious. This was a form of thinking that ran across many supporters. They indicated that, since they had suffered for a long time, such an important journey required a comfortable ride. They envisaged Canaan as a place that would provide Kenyans with rides of a better quality than what they were experiencing in present circumstances. As one of the memes, purported to be posted by Taxify (an app-based taxi) demonstrates: "KES 156129211233. Prices may vary due to traffic, weather and other factors. Estimates does not include discounts" (@ingrid_donnet).

In interviews published in The Pulse Kenya, an online magazine, Kenyans on Nairobi's streets were interviewed about their impending Canaan journey. These interviews were intended to be humorous. Those interviewed ruled out walking as a means of going to Canaan. Notable was one lady who sarcastically laughed at the thought of a trip to Canaan being undertaken on foot or by matatu. Most of them imagined themselves taking a flight to $\mathrm{Ca}$ naan. Even though most of them had never flown, they said they could not journey to their dream world on foot. The alternative to flying was using the newly-launched trains on a Standard Gauge Railway. This shows how different people visualised Canaan vicariously through a choice of their ideal means of transport, time taken, and where Canaan was situated. There were those who thought of it as a faraway land that you had to fly to and others who thought it was within Kenya but had to be accessed by special means.

Like the journey undertaken by the Israelites that was full of hurdles and took them through the desert and the sea over a long period of time, the Kenyan Canaan journey was not without obstacles. Odinga seemed to prepare his supporters for such an eventuality through his speeches: "Our journey is full of trials and tribulations, there are snakes and crocodiles in river Jordan, but this will not stop NASA from going to Canaan. We will be followed by soldiers of Pharaoh" (R. Odinga, "Confident of reaching Canaan").

This belief formed the basis upon which the online groups galvanised their supporters to overcome the obstacles that came their way. The idea of obstacles is part and parcel of the journey motif and Mortimer notes that "the very notion of travel calls for a series of binary opposition for journeys are desired or feared, successful or thwarted, individual or collective" (169). Referring to the Bible, when the Israelites were on the verge of being taken back by Egyptians as the sea of Shama lay before them. Odinga says: "When they got to the sea of Shama, and Pharaoh's soldiers were on their backs, Moses was really perturbed seeing Pharaoh's soldiers and a mass of water a head of him [...] They suffered in Sinai desert for many years until some of them almost gave up and stated blaming Moses for taking them out of Egypt" (R. Odinga, "Confident of reaching Canaan"). Odinga said this in order to prepare his supporters for the obstacles ahead, a call that was picked up by his online supporters.

Most of the obstacles encountered in the Kenyan journey were given a biblical interpretation and situated within the expected and already laid out path of the trip to Canaan. After the defeat at the ballot in an election that was purported to be rigged, NASA went to court. The filing of the court case was viewed as a pre-determined biblical process that Kenyans had to follow too. Joshua (Odinga), as the person leading the people, is temporally halted in his pursuit and the judges (in Kenyan courts) take over the temporal reign. One of the tweets reads, "After the book of Joshua comes judges then the book of Kings, we are in Jerusalem, Canaan we can see you" (@ntvkenya). In the natural progression of the journey, as laid out in the Bible, there is the book of Joshua, followed by Judges then finally Kings. Therefore, the culmination of their journey is the coronation of their King. While the court case was ongoing, the police kept vigil and could not allow people to access the courts or even the 
court compound. There was a feeling of disenfranchisement among people as expressed on many social networks. However, on the day when the many Jubilee supporters, whom the NASA supporters felt were being favourably treated by the police were at the courts, the bees attacked them. This led to a tweet being posted based on a biblical verse that implied it was God's effort to support the Canaan journey. In Exodus 23:28, posted as a tweet, God says, "And I will send the bees ahead of you to drive your enemy out of your way" (@Ochako_D). The NASArites argued that God saw how they had been abandoned and harassed by the police and, in their defence, sent the bees. As a rejoinder, quoting the same verse, one of the Jubilee supporters noted that the enemies referred to in the verse were Hivites, Canaanites, and Hittites. The NASArites referred to themselves as Canaanites and the bees were meant to attack the Canaanites. Each online group sent messages that backed their side of the narrative, pushing for a psychological victory in the online performances. The whole Canaan debate brought out the conversation about people's dreams and yearnings in their physical journey that was symbolically played out on the internet.

Those who endeavoured to undertake the physical journey saw it as a milestone that would better their lives and that, despite the varied means of transport, they were all travelling, as a group, to the Promised Land, underscoring the purpose of a journey and the role of literature in general as seeking the ideal. Mortimer (169) argues that journeys "involve experiences of discovery and/or experiences of spiritual growth and renewal". There was an underlying movement of different forms in the online interactions and speeches given at political rallies. There is a movement from first liberation to second liberation. These different phases signify a movement which those who support the changes see as a positive progression towards a better life. The interplay between NASArites and Jubilants was meant to either show positive movement or the lack of it. The expectations were in line with the motivation for the biblical journey for the Israelites that is premised on the allures of Canaan. In the book of Exodus, God promises the Israelites a broad land flowing with milk and honey, after freeing them from the yoke of Pharaoh, a life of slavery: "I have come to deliver them out of the land of Egyptians, and to bring them out of that land to a good, and broad land, a land flowing with milk and honey". It is the hope and the allures of Canaan that drive the Israelites' motivated journey to the Promised Land.

Whereas the leaders had promises based on what they hoped to achieve once they won the election, their supporters had all kinds of imaginings about their Canaan dream journey. The Canaan dream seems to draw a sense of agreement in how it is visualised as a desired place among participants. As Hall avers, "we are able to communicate because we share broadly the same conceptual maps thus make sense of or interpret the world in a roughly similar ways [...] we are able to build up a shared culture of meanings and thus construct a social world which we inhabit together" (4). Similarly, Jung notes that "There exists a second psychic system of a collective, universal, and impersonal nature which is identical in all individuals. This collective unconscious does not develop individually but is inherited. It consists of pre-existing forms, the archetypes, which can only become conscious secondarily and which give definite form to certain contents" (99). Thus, I see Kenyans united in the dream of travel despite their affiliation pointing to the common archetype across a political divide.

The online exchanges were spiced with humour that purged negative emotions. Kenyans were able to poke fun at those on the opposing side of the political divide with minimal emotional injury. Because mainstream media is controlled by the political classes and government machinery, the internet became a safe space, owing to anonymity through use of pseudonyms, for the ordinary people to emotionally express themselves. There were various thoughts on this dream but with a clear understanding that, wherever Canaan is, it was not an abandonment of the physical boundary of Kenya as a country and as an idea. The variation in thoughts echo Hall's view that "there is a constant sliding of meaning in all interpretation, a margin - something in excess of what we intend to say-in which other meanings overshadow the statement or the text, where other associations are awakened to life, giving what we say a different twist" (18). Despite variants of interpretation given relative to inherent biases of the audiences, Kenyans saw a future rooted in Canaan online despite party and tribal affiliation.

\section{Conclusion}

In this article, I have examined how social media, as a platform that allows the play of emerging genres, was used to bring Kenyans together and allow the participants to dream the ideal future of the nation as the Promised Land of Canaan. I explored how Raila Odinga, through his mediatised online speeches, portrayed himself as the hero with a quest to take Kenyans to Canaan. Through his speeches as captured online, he gave inspirational biblical analogies that set Kenyans on a symbolic Canaan dream journey played out on internet platforms. I revealed a journey motif that was brought out on online platforms by Kenyans that were bound together not just by political 
affiliation but also through social media in an attempt to undertake a journey to an imaginary symbolic Canaan. In this article I demonstrated that Kenyans imagined the journey to Canaan online as a symbolic physical journey that employs different means of transport ranging from walking, taking a taxi, to flying. Yet, as they take these forms of transport, they visualise Canaan as a land without and within Kenyan borders to which one must undergo a journey of transformation to belong to. On arrival in Canaan, I further illustrated, Kenyans will be transformed socially, economically, and politically, though depending on the political divide, this change would either be positive or negative. I have demonstrated how cyber space as a performance arena affords the online performers a degree of anonymity that allows for creative expression and imaginings in a technologically-oriented world and allows for the performance of emerging genres.

\section{Works Cited}

@ingrid_donnet (Ingrid), “Heee...... tutaafford kweli.” Twitter. 2 Aug. 2017, https://twitter.com/ingrid donnet/ status/892783000617975808.

@ntvkenya (Ken Okoth). "After the book of Joshua comes Judges then the book of Kings, we are in Jerusalem, Canaan we see you \#SupremeCourtDecides.” Twitter. 1 Sep. 2017. https://twitter.com/ntvkenya/status/9035636607774443328.

@Ochako_D (Ochako Dagg.). “ $¥$ SupremeRuling * “And I will send the bees ahead of you to drive your enemy out of your way"*_Exodus 23:28." Twitter. 20 Sep. 2017. https://twitter.com/Ochako D/status/910471834549866496.

@ (@okolako(sokolako). "Canaan-bound bus stopped by NTSA, chang'aa-happy driver arrested.” Twitter. 30 Jul. 2017. https:// twitter.com/Sokolako/status/891737649525936128/photo/1.

@VictorKipronoKl (Rabbi). "With or without ferries Canaan is a reality \#FerryImefika." Twitter. 3 Aug, 2017, https:// twitter.com/VictorKipronoKl/status/893138346700140547.

Auslander, Philip. Liveness: Performance in a Mediatized Culture. Routledge, 2008.

Couldry, Nick. "Liveness, 'reality,' and the mediated habitus from television to the mobile phone." The communication review vol. 7, no. 4, 2004, pp. 353-61, 2004. DOI: https://doi.org/10.1080/10714420490886952.

Dixon, Steven Digital Performance: A History of New Media in Theatre, Dance, Performance Art and Installation. MIT P, 1995.

Finnegan, Ruth. "How oral is oral literature?" Bulletin of the School of Oriental and African studies vol. 37, no. 1, pp. 52-64, 1974. https://www.jstor.org/stable/614104.

Hall, Stuart. "The work of representation." Representation: Cultural representations and signifying practices, edited by Stuart Hall. SAGE, 1997, 13-74.

Jung, Carl Gustav. "The concept of the collective unconscious." Collected Works vol. 9, no. 1, 1936, pp 99-104.

Kaschula, Russell H. "Exploring the oral-written interface with particular reference to Xhosa oral poetry." Research in African Literatures vol. 28, no. 1, 1997, pp. 173-91. https://www.jstor.org/stable/3819927.

"Technauriture as a Platform to Create an Inclusive Environment for the Sharing of Research." Searching for Sharing: Heritage and Multimedia in Africa, edited by Daniela Merolla and Mark Turin. Open Book, 2017, pp. 41-59.

Kim, Suk-Young. Oxford Research Encyclopedia of Literature. Oxford U P, 2016.

King James Bible. Proquest, 1996.

Lawson, Gerard. "The hero's journey as a developmental metaphor in counseling." The Journal of Humanistic Counseling, Education and Development, vol. 44, no. 2, 2005, pp. 134-44.

Mnenuka, Angelus. "Online Performance of Swahili Orature: The Need for a New Category?" Eastern African Literary and Cultural Studies vol. 5, no. 3-4, 2019, pp. 274-97. DOI: https://doi.org/10.1080/23277408.2019.1685752.

Mortimer, Mildred. "African journeys." Research in African Literatures vol. 22, no. 2, 1991, pp. 169-75.

Odinga, Jaramogi Oginga. Not Yet Uhuru: An Autobiography. East African Educational, 1967.

Odinga, Raila. "NASA leader Raila Odinga is confident of reaching Canaan." YouTube. Uploaded by KTN News Kenya. 15 Oct. 2017. https://youtu.be/YRkC8y89nlA?t=31.

"Raila's final campaign address at the Nairobi Uhuru Park Rally." YouTube. Uploaded by NTV Kenya. 5 Aug. 2017. https://youtu.be/ONd8ye-wfb4.

Pulse Live Kenya. "Kenyans excited reactions four days to Canaan." YouTube. Uploaded by Pulse Live Kenya. 4 Aug. 2017. https://youtu.be/4IIcll-12DQ.

SDE. "Hilarious memes as Kenyans react to popular Canaan trip." The Sunday Standard. 2017. https://www.standardmedia. co.ke/entertainment/local-news/2001250803/hilarious-memes-as-kenyans-react-to-popular-canaan-trip \# 